Article

\title{
Delayed Rehabilitation Protocol after Rotator Cuff Repair
}

\author{
Alessandra Berton ${ }^{1}$, Sergio De Salvatore ${ }^{1, * \mathbb{D}}$, Vincenzo Candela ${ }^{1}$, Gabriele Cortina ${ }^{1}{ }^{\mathbb{D}}$, \\ Daniela Lo Presti $^{2}{ }^{-0}$, Carlo Massaroni ${ }^{2}{ }^{10}$, Stefano Petrillo ${ }^{1}$ and Vincenzo Denaro ${ }^{1}$
}

1 Department of Orthopaedic and Trauma Surgery, Campus Bio-Medico University, Via Alvaro del Portillo, 200, Trigoria, 00128 Rome, Italy; a.berton@unicampus.it (A.B.); v.candela@unicampus.it (V.C.); g.cortina@unicampus.it (G.C.); s.petrillo@unicampus.it (S.P.); denaro@unicampus.it (V.D.)

2 Laboratory of Measurement and Biomedical Instrumentation, Campus Bio-Medico University, Via Alvaro del Portillo, 200, Trigoria, 00128 Rome, Italy; d.lopresti@unicampus.it (D.L.P.);

c.massaroni@unicampus.it (C.M.)

* Correspondence: sergio.desalvatore@gmail.com; Tel.: +39-3290140454

Received: 21 November 2020; Accepted: 24 December 2020; Published: 26 December 2020

check for updates

\begin{abstract}
Rotator cuff tears are a frequent cause of shoulder pain that often require arthroscopic repair. After surgery an intense and well-studied rehabilitation protocol is needed to obtain the complete recovery of shoulder function. Fifty patients, who sustained arthroscopic rotator cuff repair for symptomatic, atraumatic and full-thickness supraspinatus tendon tear, were involved. According to our rehabilitation protocol, during the first four postoperative weeks, the arm was supported with an abduction sling pillow, and pendulum exercises, table slide and active elbow extension and flexion were conceded. Outcome measures (Oxford shoulder score (OSS), simple shoulder test (SST), patient-reported satisfaction), shoulder function (range of motion (ROM) and muscle strength), and MRI examination were evaluated. The mean OSS score and SST score increased from 16 to 30.2 and from 5.3 to 11.4, respectively. Patient-reported satisfaction was $96 \%$. At 12 months, patients improved ROM and muscle strength. Postoperative passive anterior elevation was 176; external rotation averaged 47; internal rotation was 90 . Postoperative muscle strength during anterior elevation was $8.3 \pm 2.2 \mathrm{~kg}$, internal rotation $6.8 \pm 3 \mathrm{~kg}$, external rotation $5.5 \pm 2.3 \mathrm{~kg}$. Five out of seven patients with recurrent tears evaluated their results as satisfactory. They reported improvements in terms of OSS and SST mean scores despite recurrent tears; therefore, they did not undergo revision surgery. The delayed postoperative physical therapy protocol was associated with improvements in the outcome measures and shoulder function compared to the preoperatory state and rotator cuff healing demonstrated by MRI.
\end{abstract}

Keywords: rotator cuff; tears; physical therapy; retear; stiffness; rehabilitation

\section{Introduction}

Rotator cuff tears are among the most prevalent musculoskeletal disorders for which patients need therapy [1,2]. The etiology of rotator cuff tears is multifactorial $[1,3]$. It is due to the combination of intrinsic and extrinsic factors whose relative contributions remain to be determined. Intrinsic factors result in progressive insults to the rotator cuff via tensile overload, aging, or microvascular supply. Extrinsic factors can damage the rotator cuff through compression of tendons by bony impingement or direct pressure from the surrounding soft tissue. Other factors, such as hyperglycaemia, diabetes, obesity or metabolic syndrome, and nicotine have been associated with rotator cuff tears.

Arthroscopic surgery is a valid therapeutic option that aims to repair rotator cuff tears $[4,5]$, particularly in patients in whom conservative treatment has not produced good results in terms of 
shoulder pain and function. Although this surgical technique is widely spread, the ideal postoperative rehabilitation protocol is still debated. Timelines for immobilization, frequency, and ROM format after rotator cuff repair are not standardized [6].

Postoperative rehabilitation goals are to preserve the repaired muscle and tendon and recover the biomechanics and functionality of the shoulder by balancing the scapulothoracic and glenohumeral force couples [7]. Several factors, as age [8,9], diabetes [10,11], smoking [12], activity level, topography and extent of the tear [8], tendon quality, fatty infiltration, atrophy of muscles [9,12-14], and surgical repair approach $[15,16]$ should be analyzed to choose the more suitable rehabilitation protocol. These variables can affect the repaired tendon's healing process and the outcome [17-22].

After rotator cuff repair, several rehabilitation protocols have been described, and these are divided into those with early mobilization and those with delayed mobilization [23,24]. The early mobilization has the purpose of preventing postoperative stiffness, fatty infiltration, and muscle atrophy, but it may also decrease the possibility of tendon healing [25-27]; on the contrary, delayed mobilization, theoretically, would protect the tendon healing, but it would increase the risk of stiffness. Moreover, in the literature, several studies have shown how most rotator cuff re-tears occur within 3 to 6 months after surgery, which supports delayed mobilization protocol $[28,29]$. This study aims to assess the clinical outcomes and tendon healing confirmed by MRI in patients who received arthroscopic repair of the rotator cuff and a delayed postoperative physical therapy protocol that aimed to limit early passive movements. The hypothesis stated is that delayed motion after arthroscopic repair might reduce failure without adversely affecting ROM.

\section{Materials and Methods}

\subsection{Inclusion and Exclusion Criteria}

Inclusion criteria were age 45-70 years; symptomatic, atraumatic, and isolated full-thickness supraspinatus tendon tear confirmed with MRI, tear size $\leq 1 \mathrm{~cm}$; complete ROM of the shoulder.

Exclusion criteria were prior shoulder surgery; glenohumeral osteoarthritis confirmed with radiological imaging; neurological disease or language barriers; tears involving 2 or 3 tendons; muscle fatty degeneration > of stage 2 according to Goutallier classification [30]; muscle atrophy evaluated with Tangent sign, exceeding stage 2 [31]; acute-on-chronic tears (after a traumatic event in a shoulder with preceding episodes of symptoms); impossibility to undergo MRI scan for any reason.

The sample size calculation was based on the OSS. Assuming an Effect Size 0.97 [32] at a power of $80 \%$ with a significance level of 0.05 , a total of 21 patients was required.

The study was approved by the local ethics committee (Ethics Committee Campus Bio-Medico University of Rome, Prot ComEt 37/16 CBM).

\subsection{Operative Procedure}

An experienced orthopaedic surgeon performed surgical procedures in all the patients. Diagnostic arthroscopy was followed by subacromial decompression and biceps tenotomy in all patients. The surgical repair was performed by one row of double-loaded suture anchors.

\subsection{Postoperative Rehabilitation Protocol}

During the first four weeks, the arm was supported with an abduction sling pillow, and pendulum exercises, table slide, and active elbow extension and flexion were allowed. Small circular pendulum exercises were performed using the torso to move the arm by rocking body weight. For table slide exercise, the patient slides the hand of the operated shoulder forward on a surface by advancing the chest towards the table. Patient started therapy four weeks after surgery, working with the therapist 1-3 x/week, and at home on the other days. From week 5 to 8 , the patient performed passive forward elevation; passive external rotation; and from week 5, active-assisted ROM to tolerance. From week 8 to 10 , the patient progressed towards active ROM to tolerance. After week 10, the patient began the 
rehabilitation of the deltoid, scapular stabilizers, and the rotator cuff with concentric and eccentric exercise strengthening

Postoperative rehabilitation protocol was standardized. An illustrated handbook with detailed instruction of exercise and timing was given to patients and therapists. During outpatient visits, the frequency of supervised and home therapy was checked and registered.

The details of the postoperative physical therapy protocol are listed in Table 1.

Table 1. Postoperative physical therapy protocol.

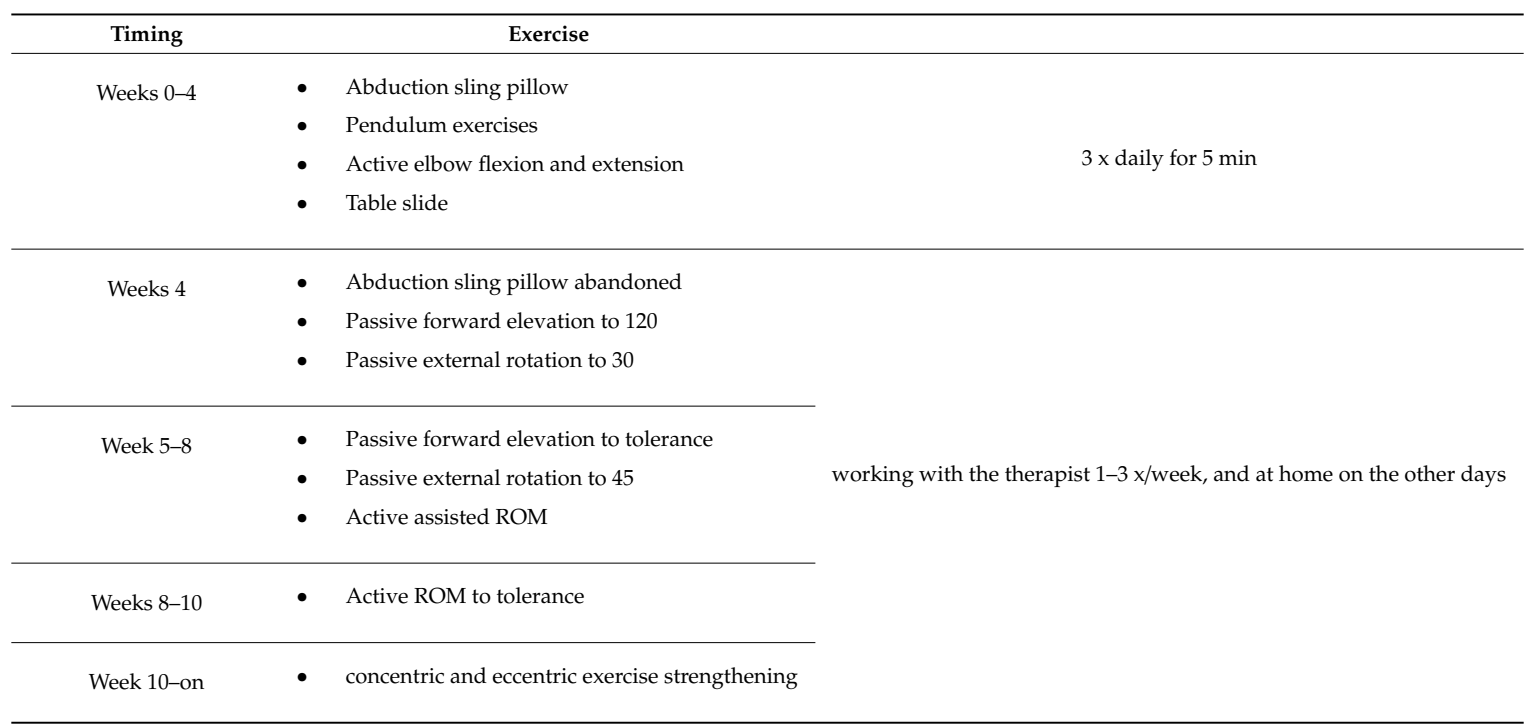

\subsection{Outcome Measures}

The clinical outcomes that were measured are the Patient-Reported Outcome Measures (PROMS), in particular, the Oxford Shoulder Score (OSS) and the Simple shoulder test (SST), and the patient-reported satisfaction preoperatively and 12 months [33,34].

- The Oxford Shoulder Score (OSS) contains 12 items that are assigned a score from 0 to 4 for each, with 0 representing the worst answer. The final score, therefore, varies between 0 and 48 [35].

- Simple shoulder test (SST) consists of 12 elements that can be answered with 0 or 1 . The total score varies between 0 and 12 [36].

- Patient-reported satisfaction is a test in which patients were asked to evaluate their results as satisfactory or unsatisfactory.

\subsection{Shoulder Function}

Shoulder ROM and muscle strength were measured both before the surgery and at 1-year follow-up. With the patient in a supine position, the ranges of passive anterior elevation, external and internal rotation were measured using a standard universal goniometer; whereas muscle strength during active anterior elevation, external and internal rotation was measured with a dynamometer [37]. Two orthopaedic surgeons, who were familiarized with the procedure, performed all measurement following a standardized methodology [37]. The procedure started with goniometric measurements of ROM in different positions. Supine position guaranteed stabilization of the scapula and trunk. One examiner performed passive ROM, and the other examiner handled the goniometer to perform the measurement. Subsequently, strength measurements with dynamometer were performed during active anterior elevation and external and internal rotation. 


\subsection{MRI Examination of Cuff Healing}

The MRI scans were acquired by sagittal oblique, spin-echo coronal oblique, and axial T2-weighted image [repetition time (RT): $3200 \mathrm{~ms}$; echo time (ET): $85 \mathrm{~ms}$ ] both pre-operation and 1-year follow-up. Preoperatively, the location, size, and thickness of rotator cuff tears were recorded. Postoperatively MRI was used to assess cuff integrity. Whether there was a gap in the rotator cuff at MRI scans, a retear condition was defined.

\section{Results}

\subsection{Demographics}

Fifty patients ( 36 males and 14 females) were enrolled in the study. The mean age was $63.6 \pm 6.7$ years, ranging from 49 to 70 years. The dominant arm was injured in 38 patients.

\subsection{Outcome Measures}

The mean OSS score and SST score improved from 16 to $30.2(p=0.03)$ and from 5.3 to 11.4 $(p=0.04)$, respectively. Patient-reported satisfaction was $96 \%$. Table 2.

Table 2. Results summary.

\begin{tabular}{ccc}
\hline Outcome & Preoperative & Postoperative \\
\hline OSS & 16 & 30.2 \\
\hline SST & 5.3 & 11.4 \\
\hline Passive Anterior Elevation & 160 & 176 \\
\hline Passive Internal Rotation & 85 & 90 \\
\hline Passive External Rotation & 44 & 47 \\
\hline Muscle Strength Anterior Elevation & $2.1 \pm 1.2 \mathrm{~kg}$ & $8.3 \pm 2.2 \mathrm{~kg}$ \\
\hline Muscle Strength Internal Rotation & $3.4 \pm 2 \mathrm{~kg}$ & $6.8 \pm 3 \mathrm{~kg}$ \\
\hline Muscle Strength External Rotation & $2.5 \pm 1.5 \mathrm{~kg}$ & $5.5 \pm 2.3 \mathrm{~kg}$ \\
\hline Recurrent tears & - & 7 patients \\
\hline
\end{tabular}

\subsection{Shoulder Function}

At 12 months, patients improved range of motion compared to preoperative condition. Preoperative passive anterior elevation averaged 160, external rotation averaged 44, and internal rotation averaged 85. Postoperative passive anterior elevation was 176, external rotation averaged 47 , internal rotation was 90. Muscle strength improved too. Preoperative average muscle strength during anterior elevation was $2.1 \pm 1.2 \mathrm{~kg}$, internal rotation $3.4 \pm 2 \mathrm{~kg}$, external rotation $2.5 \pm 1.5 \mathrm{~kg}$. Postoperative average muscle strength during anterior elevation was $8.3 \pm 2.2 \mathrm{~kg}$, internal rotation $6.8 \pm 3 \mathrm{~kg}$, external rotation $5.5 \pm 2.3 \mathrm{~kg}$. Comparing postoperative muscle strength with the contralateral normal shoulder, there were no statistically significant differences $(p=0.23)$.

No patient reported biceps cramping from the biceps tenotomy (Table 2).

\subsection{MRI Examination of Cuff Healing}

The MRI investigation of the rotator cuff at 1-year follow-up showed intact and healed tendon repair in 43 of 50 patients. There were seven recurrent tears of which 5 showed improvements in terms of OSS and SST score despite recurrent tears. For these reasons, they did not undergo revision surgery. Two patients with recurrent tears rated their outcome as unsatisfactory and underwent revision surgery. The reason for retears could not be identify, as retears are a multifactorial issue. In patients that 
experienced recurrent tears, preoperative tear size and rehabilitation protocol was similar to patients who healed.

\section{Discussion}

There is no formal consensus about which is the best rehabilitation protocol of surgically repaired rotator cuff. This study aimed to assess clinical outcomes and tendon healing in patients that performed a delayed postoperative physical therapy protocol that limited early passive movements after rotator cuff repair. We observed good clinical outcomes and shoulder ROM in patients undergone delayed motion after arthroscopic repair. This study did not allow deriving absolute conclusions about the best rehabilitation protocol of surgically repaired rotator cuff, but it is the first step to carry on further studies.

Retear and stiffness are the main concerns of postoperative rehabilitation after rotator cuff repair. The failure to heal or the risk of retear after surgical repair of small to intermediate tears are relatively frequent and range from $7 \%$ to $41 \%$ [14,28,29,38,39]. For massive tears, many studies have shown worrisome re-tear rates ranging from 20 to 94\%, often associated with poor clinical outcomes [40-42]. The postoperative period between six and twenty-six weeks is a risky period where the possibility of failure of tendon healing or retear is more frequent. In fact, Ahmad et al. highlight that at six weeks post-surgery, there is 152 times the risk of re-tear; meanwhile, at 26 weeks, there is 40 times the risk of re-tear [43]. Retears of massive lesion have been observed to occur earlier than small or intermediate ones $[18,44,45]$. From a biomechanical point of view, normal levels of elasticity or strength of the repaired tendon are not restored until at least six months after surgery $[46,47]$. This is the reason why prevent excessive loading, and judicious use of ROM is generally suggested.

On the other hand, stiffness should be suspected especially in the first three months after arthroscopic rotator cuff repair $[48,49]$. Several authors recommended early passive range of motion after rotator cuff repair to decrease the possibility of developing potential adhesion and stiffness [50-52]. Animal studies showed that the sharpay fibres, which are responsible for maintaining the repair, appear after 12 weeks and, up to the 15 weeks, the bone-tendon junction is still not quite mature [53]. Furthermore, early movement restriction did not result in long-term stiffness after arthroscopic rotator cuff repair and may improve tendon healing rate [54]. An exuberant healing response has been observed in patients with shoulder stiffness [55].

To date, there is no consensus about which is the best rehabilitation protocol of surgically repaired rotator cuff, and available studies are heterogeneous in terms of timelines for immobilization and ROM restrictions, precluding the possibility to reach definitive conclusions and recommendations [24]. Cuff et al. compared early and delayed passive motion demonstrating that there are no significant differences in terms of patient satisfaction, rotator cuff healing, or range of motion between the two groups. Furthermore, the study showed a slightly higher rotator cuff healing rate in favour of patients who received a delayed passive movement protocol. Conversely, a lower trend towards retear rates was observed in the group that received an early rehabilitation protocol [56]. Riboh and Garrigues compared early and delayed rehabilitation protocol and concluded that there was no difference in cuff re-tears rates at one year for patients with tears less than $3 \mathrm{~cm}$ [57]. Kluczynski, showed an increased risk of cuff tear recurrence in patients with large tears between $3 \mathrm{~cm}$ and $5 \mathrm{~cm}$ who underwent an early rehabilitation protocol [58].

In this study, we observed that OSS, SST and shoulder function of patients undergone delayed postoperative physical therapy protocol improved compared to the preoperative state, and postoperative MRI demonstrated rotator cuff healing. Pendulum exercise and table slide are a good choice for early mobilization because they produce only low levels of supraspinatus contraction reducing the risk of recalcitrant postoperative stiffness in patients with risk factors as calcific tendinitis or adhesive capsulitis. Moreover, those exercises are easy for patients to perform, and the delayed need for postoperative rehabilitation professional may be economically advantageous.

We note that the patient's compliance with the rehabilitation program is essential. This observation was empirical and needs further objective evaluations that will be the subject of future studies. 
Communication and coordination between the surgeon, rehabilitation professional and patient were critical to optimize outcomes. However, it is evident for those who face with patients, that compliance with a rehabilitation program is challenging to obtain and to monitor. Patients do not always follow the limits of shoulder movement. In particular, those with high expectations for their return to activity tend to move their shoulder earlier to accelerate the rehabilitation process. Despite that, they can experience good clinical results. Moreover, daily shoulder motions, such as brushing teeth, combing hair, cooking, and eating, can contribute to the rehabilitation and should be considered as additional exercises. At present, the effect of the rehabilitation program and daily shoulder motions on tendon healing is not known. There is an urgent need to improve rehabilitation monitoring, providing the surgeon with a practical and easy way to check the patient's compliance and personalize rehabilitation protocol based on the feedback of shoulder motion.

This study has several strengths. Strict inclusion and exclusion criteria allowed selecting a homogeneous population of patients with symptomatic, atraumatic and isolated full-thickness supraspinatus tendon tear, size $\leq 1 \mathrm{~cm}$, rather than patients with generic rotator cuff tears. This element is of relevance since the response to treatment can likely be influenced by the underlying characteristics of rotator cuff tears. Specific and validated outcome measures were used to collect the outcomes of delayed postoperative physical therapy protocol after rotator cuff surgery. This made it possible to obtain easily understandable and shareable data, which can be directly compared with those already available, as well as usable for future studies and meta-analyses. The use of MRI provides an objective method to demonstrate rotator cuff integrity or retear. Definition of retear based on MRI is of relevance as not all patients with retear complain of pain or functional limitation [59].

The main weakness of this study was the lack of a control group. However, the key aim was not to draw absolute conclusions about delayed postoperative physical therapy after rotator cuff surgery but rather to consider whether the use of a delayed postoperative physical therapy is associated with good clinical outcomes and tendon healing.

\section{Conclusions}

The delayed postoperative physical therapy protocol that we presented in this study was associated with improvements in OSS, SST and shoulder function compared to the preoperative state, and rotator cuff healing demonstrate by MRI. Even if absolute conclusions about the best rehabilitation protocol of surgically repaired rotator cuff cannot be derived, it is the first step to carry on further studies focused on limited early passive movements after rotator cuff repair.

Author Contributions: Conceptualization, S.D.S.; data curation, A.B.; formal analysis, V.C.; investigation, V.C.; resources, C.M.; software, G.C. and D.L.P.; supervision, S.D.S.; validation, D.L.P. and S.P.; writing-original draft, A.B.; writing - review and editing, G.C and V.D. All authors have read and agreed to the published version of the manuscript.

Funding: The authors declare that they have no conflicts of interest and no funding source.

Institutional Review Board Statement: The study was conducted according to the guidelines of the Declaration of Helsinki, and approved by the local ethics committee (Ethics Committee Campus Bio-Medico University of Rome, Prot ComEt 37/16 CBM).

Informed Consent Statement: Informed consent was obtained from all subjects involved in the study.

Data Availability Statement: The data presented in this study are available on request from the corresponding author. The data are not publicly available due to privacy.

Conflicts of Interest: The authors declare no conflict of interest.

\section{References}

1. Longo, U.G.; Berton, A.; Papapietro, N.; Maffulli, N.; Denaro, V. Epidemiology, genetics and biological factors of rotator cuff tears. In Medicine and Sport Science; Maffulli, N., Ed.; KARGER: Basel, Switzerland, 2011; Volume 57, pp. 1-9. ISBN 978-3-8055-9815-6. 
2. Salvatore, G.; Longo, U.G.; Candela, V.; Berton, A.; Migliorini, F.; Petrillo, S.; Ambrogioni, L.R.; Denaro, V. Epidemiology of rotator cuff surgery in Italy: Regional variation in access to health care. results from a 14-year nationwide registry. Musculoskelet. Surg. 2020, 104, 329-335. [CrossRef]

3. Longo, U.G.; Margiotti, K.; Petrillo, S.; Rizzello, G.; Fusilli, C.; Maffulli, N.; De Luca, A.; Denaro, V. Genetics of rotator cuff tears: No association of col5a1 gene in a case-control study. BMC Med. Genet. 2018, $19,217$. [CrossRef] [PubMed]

4. Ryösä, A.; Laimi, K.; Äärimaa, V.; Lehtimäki, K.; Kukkonen, J.; Saltychev, M. Surgery or conservative treatment for rotator cuff tear: A meta-analysis. Disabil. Rehabil. 2017, 39, 1357-1363. [CrossRef] [PubMed]

5. Grobet, C.; Audigé, L.; Eichler, K.; Meier, F.; Brunner, B.; Wieser, S.; Flury, M. Cost-utility analysis of arthroscopic rotator cuff repair: A prospective health economic study using real-world data. Arthrosc. Sports Med. Rehabil. 2020, 2, e193-e205. [CrossRef] [PubMed]

6. Longo, U.G.; Risi Ambrogioni, L.; Berton, A.; Candela, V.; Carnevale, A.; Schena, E.; Gugliemelli, E.; Denaro, V. Physical therapy and precision rehabilitation in shoulder rotator cuff disease. Int. Orthop. 2020, 44, 893-903. [CrossRef]

7. Kawano, Y.; Matsumura, N.; Murai, A.; Tada, M.; Matsumoto, M.; Nakamura, M.; Nagura, T. Evaluation of the translation distance of the glenohumeral joint and the function of the rotator cuff on its translation: A cadaveric study. Arthrosc. J. Arthrosc. Relat. Surg. 2018, 34, 1776-1784. [CrossRef]

8. Manaka, T.; Ito, Y.; Matsumoto, I.; Takaoka, K.; Nakamura, H. Functional recovery period after arthroscopic rotator cuff repair: Is it predictable before surgery? Clin. Orthop. Relat. Res. 2011, 469, 1660-1666. [CrossRef]

9. Kuptniratsaikul, V.; Laohathaimongkol, T.; Umprai, V.; Yeekian, C.; Prasathaporn, N. Pre-operative factors correlated with arthroscopic reparability of large-to-massive rotator cuff tears. BMC Musculoskelet. Disord. 2019, 20. [CrossRef]

10. Yang, L.; Zhang, J.; Ruan, D.; Zhao, K.; Chen, X.; Shen, W. Clinical and structural outcomes after rotator cuff repair in patients with diabetes: A meta-analysis. Orthop. J. Sports Med. 2020, 8, 232596712094849. [CrossRef]

11. Hong, C.-K.; Chang, C.-J.; Kuan, F.-C.; Hsu, K.-L.; Chen, Y.; Chiang, C.-H.; Su, W.-R. Patients with diabetes mellitus have a higher risk of tendon retear after arthroscopic rotator cuff repair: A meta-analysis. Orthop. J. Sports Med. 2020, 8, 232596712096140. [CrossRef]

12. Jensen, A.R.; Taylor, A.J.; Sanchez-Sotelo, J. Factors influencing the reparability and healing rates of rotator cuff tears. Curr. Rev. Musculoskelet. Med. 2020, 13, 572-583. [CrossRef] [PubMed]

13. Gladstone, J.N.; Bishop, J.Y.; Lo, I.K.Y.; Flatow, E.L. Fatty infiltration and atrophy of the rotator cuff do not improve after rotator cuff repair and correlate with poor functional outcome. Am. J. Sports Med. 2007, 35, 719-728. [CrossRef] [PubMed]

14. Lee, Y.S.; Jeong, J.Y.; Park, C.-D.; Kang, S.G.; Yoo, J.C. Evaluation of the risk factors for a rotator cuff retear after repair surgery. Am. J. Sports Med. 2017, 45, 1755-1761. [CrossRef] [PubMed]

15. Galatz, L.M.; Rothermich, S.Y.; Zaegel, M.; Silva, M.J.; Havlioglu, N.; Thomopoulos, S. Delayed repair of tendon to bone injuries leads to decreased biomechanical properties and bone loss. J. Orthop. Res. 2005, 23, 1441-1447. [CrossRef]

16. Killian, M.L.; Cavinatto, L.; Galatz, L.M.; Thomopoulos, S. The role of mechanobiology in tendon healing. J. Shoulder Elb. Surg. 2012, 21, 228-237. [CrossRef]

17. Longo, U.G.; Berton, A.; Khan, W.S.; Maffulli, N.; Denaro, V. Histopathology of rotator cuff tears. Sports Med. Arthrosc. Rev. 2011, 19, 227-236. [CrossRef]

18. Longo, U.G.; Forriol, F.; Campi, S.; Maffulli, N.; Denaro, V. Animal models for translational research on shoulder pathologies: From bench to bedside. Sports Med. Arthrosc. Rev. 2011, 19, 184-193. [CrossRef]

19. Maffulli, N.; Longo, U.G.; Berton, A.; Loppini, M.; Denaro, V. Biological factors in the pathogenesis of rotator cuff tears. Sports Med. Arthrosc. Rev. 2011, 19, 194-201. [CrossRef] 
20. Maffulli, N.; Margiotti, K.; Longo, U.G.; Loppini, M.; Fazio, V.M.; Denaro, V. The genetics of sports injuries and athletic performance. Muscles Ligaments Tendons J. 2013, 3, 173-189. [CrossRef]

21. Denaro, V.; Ruzzini, L.; Longo, U.G.; Franceschi, F.; De Paola, B.; Cittadini, A.; Maffulli, N.; Sgambato, A. Effect of dihydrotestosterone on cultured human tenocytes from intact supraspinatus tendon. Knee Surg. Sports Traumatol. Arthrosc. 2010, 18, 971-976. [CrossRef]

22. Del Buono, A.; Oliva, F.; Longo, U.G.; Rodeo, S.A.; Orchard, J.; Denaro, V.; Maffulli, N. Metalloproteases and rotator cuff disease. J. Shoulder Elb. Surg. 2012, 21, 200-208. [CrossRef] [PubMed]

23. Li, S.; Sun, H.; Luo, X.; Wang, K.; Wu, G.; Zhou, J.; Wang, P.; Sun, X. The clinical effect of rehabilitation following arthroscopic rotator cuff repair: A meta-analysis of early versus delayed passive motion. Med. (Baltim.) 2018, 97, e9625. [CrossRef] [PubMed]

24. Bakti, N.; Antonios, T.; Phadke, A.; Singh, B. Early versus delayed mobilization following rotator cuff repair. J. Clin. Orthop. Trauma 2019, 10, 257-260. [CrossRef] [PubMed]

25. Papalia, R.; Franceschi, F.; Vasta, S.; Gallo, A.; Maffulli, N.; Denaro, V. Shoulder stiffness and rotator cuff repair. Br. Med. Bull. 2012, 104, 163-174. [CrossRef]

26. Huberty, D.P.; Schoolfield, J.D.; Brady, P.C.; Vadala, A.P.; Arrigoni, P.; Burkhart, S.S. Incidence and treatment of postoperative stiffness following arthroscopic rotator cuff repair. Arthrosc. J. Arthrosc. Relat. Surg. Off. Publ. Arthrosc. Assoc. N. Am. Int. Arthrosc. Assoc. 2009, 25, 880-890. [CrossRef]

27. Audigé, L.; Blum, R.; Müller, A.M.; Flury, M.; Durchholz, H. Complications following arthroscopic rotator cuff tear repair: A systematic review of terms and definitions with focus on shoulder stiffness. Orthop. J. Sports Med. 2015, 3, 232596711558786. [CrossRef]

28. Kluger, R.; Bock, P.; Mittlböck, M.; Krampla, W.; Engel, A. Long-term survivorship of rotator cuff repairs using ultrasound and magnetic resonance imaging analysis. Am. J. Sports Med. 2011, 39, 2071-2081. [CrossRef]

29. Miller, B.S.; Downie, B.K.; Kohen, R.B.; Kijek, T.; Lesniak, B.; Jacobson, J.A.; Hughes, R.E.; Carpenter, J.E. When do rotator cuff repairs fail? Serial ultrasound examination after arthroscopic repair of large and massive rotator cuff tears. Am. J. Sports Med. 2011, 39, 2064-2070. [CrossRef]

30. Somerson, J.S.; Hsu, J.E.; Gorbaty, J.D.; Gee, A.O. Classifications in brief: Goutallier classification of fatty infiltration of the rotator cuff musculature. Clin. Orthop. 2016, 474, 1328-1332. [CrossRef]

31. Rulewicz, G.J.; Beaty, S.; Hawkins, R.J.; Kissenberth, M.J. Supraspinatus atrophy as a predictor of rotator cuff tear size: An mri study utilizing the tangent sign. J. Shoulder Elb. Surg. 2013, 22, e6-e10. [CrossRef]

32. Allom, R.; Colegate-Stone, T.; Gee, M.; Ismail, M.; Sinha, J. Outcome analysis of surgery for disorders of the rotator cuff: A comparison of subjective and objective scoring tools. J. Bone Jt. Surg. Br. 2009, 91, 367-373. [CrossRef] [PubMed]

33. Longo, U.G.; Saris, D.; Poolman, R.W.; Berton, A.; Denaro, V. Instruments to assess patients with rotator cuff pathology: A systematic review of measurement properties. Knee Surg. Sports Traumatol. Arthrosc. 2012, 20, 1961-1970. [CrossRef] [PubMed]

34. Longo, U.G.; Vasta, S.; Maffulli, N.; Denaro, V. Scoring systems for the functional assessment of patients with rotator cuff pathology. Sports Med. Arthrosc. Rev. 2011, 19, 310-320. [CrossRef] [PubMed]

35. Angst, F.; Schwyzer, H.-K.; Aeschlimann, A.; Simmen, B.R.; Goldhahn, J. Measures of adult shoulder function: Disabilities of the arm, shoulder, and hand questionnaire (DASH) and its short version (QUICKDASH), shoulder pain and disability index (SPADI), American shoulder and elbow surgeons (ASES) society standardized shoulder assessment form, constant (MURLEY) score (CS), simple shoulder test (SST), oxford shoulder score (OSS), shoulder disability questionnaire (SDQ), and western Ontario shoulder instability index (WOSI). Arthritis Care Res. 2011, 63 (Suppl. 11), S174-S188. [CrossRef]

36. Godfrey, J.; Hamman, R.; Lowenstein, S.; Briggs, K.; Kocher, M. Reliability, validity, and responsiveness of the simple shoulder test: Psychometric properties by age and injury type. J. Shoulder Elb. Surg. 2007, 16, 260-267. [CrossRef]

37. Cools, A.M.; De Wilde, L.; Van Tongel, A.; Ceyssens, C.; Ryckewaert, R.; Cambier, D.C. Measuring shoulder external and internal rotation strength and range of motion: Comprehensive intra-rater and inter-rater reliability study of several testing protocols. J. Shoulder Elb. Surg. 2014, 23, 1454-1461. [CrossRef] 
38. Lafosse, L.; Brzoska, R.; Toussaint, B.; Gobezie, R. The outcome and structural integrity of arthroscopic rotator cuff repair with use of the double-row suture anchor technique. J. Bone Jt. Surg. Am. Vol. 2008, 90, 275-286. [CrossRef]

39. McElvany, M.D.; McGoldrick, E.; Gee, A.O.; Neradilek, M.B.; Matsen, F.A. Rotator cuff repair: Published evidence on factors associated with repair integrity and clinical outcome. Am. J. Sports Med. 2015, 43, 491-500. [CrossRef]

40. Galatz, L.M.; Ball, C.M.; Teefey, S.A.; Middleton, W.D.; Yamaguchi, K. The outcome and repair integrity of completely arthroscopically repaired large and massive rotator cuff tears. J. Bone Jt. Surg. 2004, 86, 219-224. [CrossRef]

41. Bedi, A.; Dines, J.; Warren, R.F.; Dines, D.M. Massive tears of the rotator cuff. J. Bone Jt. Surg. Am. Vol. 2010, 92, 1894-1908. [CrossRef]

42. Henry, P.; Wasserstein, D.; Park, S.; Dwyer, T.; Chahal, J.; Slobogean, G.; Schemitsch, E. Arthroscopic repair for chronic massive rotator cuff tears: A systematic review. Arthrosc. J. Arthrosc. Relat. Surg. 2015, 31, 2472-2480. [CrossRef] [PubMed]

43. Ahmad, S.; Haber, M.; Bokor, D.J. The influence of intraoperative factors and postoperative rehabilitation compliance on the integrity of the rotator cuff after arthroscopic repair. J. Shoulder Elb. Surg. 2015, 24, $229-235$. [CrossRef] [PubMed]

44. Zumstein, M.A.; Jost, B.; Hempel, J.; Hodler, J.; Gerber, C. The clinical and structural long-term results of open repair of massive tears of the rotator cuff. J. Bone Jt. Surg. Am. Vol. 2008, 90, 2423-2431. [CrossRef] [PubMed]

45. Iannotti, J.P.; Deutsch, A.; Green, A.; Rudicel, S.; Christensen, J.; Marraffino, S.; Rodeo, S. Time to failure after rotator cuff repair: A prospective imaging study. J. Bone Jt. Surg. 2013, 95, 965-971. [CrossRef]

46. Huegel, J.; Williams, A.A.; Soslowsky, L.J. Rotator cuff biology and biomechanics: A review of normal and pathological conditions. Curr. Rheumatol. Rep. 2015, 17, 476. [CrossRef]

47. Longo, U.G.; Petrillo, S.; Rizzello, G.; Candela, V.; Denaro, V. Deltoid muscle tropism does not influence the outcome of arthroscopic rotator cuff repair. Musculoskelet. Surg. 2016, 100, 193-198. [CrossRef]

48. Tauro, J.C.; Paulson, M. Shoulder stiffness. Arthrosc. J. Arthrosc. Relat. Surg. 2008, 24, 949-955. [CrossRef]

49. Tauro, J.C. Stiffness and rotator cuff tears: Incidence, arthroscopic findings, and treatment results. Arthrosc. J. Arthrosc. Relat. Surg. 2006, 22, 581-586. [CrossRef]

50. Brislin, K.J.; Field, L.D.; Savoie, F.H. Complications after arthroscopic rotator cuff repair. Arthrosc. J. Arthrosc. Relat. Surg. 2007, 23, 124-128. [CrossRef]

51. Thomopoulos, S.; Williams, G.R.; Soslowsky, L.J. Tendon to bone healing: Differences in biomechanical, structural, and compositional properties due to a range of activity levels. J. Biomech. Eng. 2003, 125, 106-113. [CrossRef]

52. Chang, K.-V.; Hung, C.-Y.; Han, D.-S.; Chen, W.-S.; Wang, T.-G.; Chien, K.-L. Early versus delayed passive range of motion exercise for arthroscopic rotator cuff repair: A meta-analysis of randomized controlled trials. Am. J. Sports Med. 2015, 43, 1265-1273. [CrossRef] [PubMed]

53. Edwards, P.K.; Ebert, J.R.; Littlewood, C.; Ackland, T.; Wang, A. A systematic review of electromyography studies in normal shoulders to inform postoperative rehabilitation following rotator cuff repair. J. Orthop. Sports Phys. Ther. 2017, 47, 931-944. [CrossRef] [PubMed]

54. Lee, B.G.; Cho, N.S.; Rhee, Y.G. Effect of two rehabilitation protocols on range of motion and healing rates after arthroscopic rotator cuff repair: Aggressive versus limited early passive exercises. Arthrosc. J. Arthrosc. Relat. Surg. 2012, 28, 34-42. [CrossRef] [PubMed]

55. Sonnabend, D.H.; Howlett, C.R.; Young, A.A. Histological evaluation of repair of the rotator cuff in a primate model. J. Bone Joint Surg. Br. 2010, 92-B, 586-594. [CrossRef] [PubMed]

56. Cuff, D.J.; Pupello, D.R. Prospective randomized study of arthroscopic rotator cuff repair using an early versus delayed postoperative physical therapy protocol. J. Shoulder Elb. Surg. 2012, 21, 1450-1455. [CrossRef] [PubMed]

57. Riboh, J.C.; Garrigues, G.E. Early passive motion versus immobilization after arthroscopic rotator cuff repair. Arthrosc. J. Arthrosc. Relat. Surg. 2014, 30, 997-1005. [CrossRef] 
58. Kluczynski, M.A.; Nayyar, S.; Marzo, J.M.; Bisson, L.J. Early versus delayed passive range of motion after rotator cuff repair: A systematic review and meta-analysis. Am. J. Sports Med. 2015, 43, 2057-2063. [CrossRef]

59. Yang, J.; Robbins, M.; Reilly, J.; Maerz, T.; Anderson, K. The clinical effect of a rotator cuff retear: A meta-analysis of arthroscopic single-row and double-row repairs. Am. J. Sports Med. 2017, 45, 733-741. [CrossRef]

Publisher's Note: MDPI stays neutral with regard to jurisdictional claims in published maps and institutional affiliations.

(C) 2020 by the authors. Licensee MDPI, Basel, Switzerland. This article is an open access article distributed under the terms and conditions of the Creative Commons Attribution (CC BY) license (http://creativecommons.org/licenses/by/4.0/). 